\title{
INCREASE SUICIDAL MORTALITY RATE AMONG FEMALES IN DISTRICT
} PESHAWAR

\author{
Farooq Ahmed Abro', Rizwan Zafar Ansari², Muhammad Yousaf ${ }^{3}$, Riaz Gul², Anwar UI Haq², \\ Zahid Hussain Khalil ${ }^{4}$ \\ 1. Frontier Medical College \\ 2. Northwest School of Medicine \\ 3. Khyber Medical College \\ 4. Kabir Medical College
}

\section{ABSTRACT:}

\section{OBJECTIVE:}

To study increased suicidal mortality rate among females in district Peshawar.

\section{METHODOLOGY:}

The bodies of women in the reproductive age who died because of fatal deliberate self-harming were examined at Forensic Medicine Department Khyber Medical College, Peshawar from January 2015 to September 2015.

\section{RESULTS:}

Forty-four bodies of females were autopsied. 13 (30\%) were adolescents between the age of 10-18 years. $31(70.4 \%)$ were aged between 19-48 years. 33 of the victims committed suicide due to healthrelated issues. $28(64 \%)$ victims used poisons. In almost all cases $(n=38)$ the incident happened when the victim was alone in house or left unattended. 30 (68\%) victims were brought to hospitals for treatment. 13 were found to have recurrent attempt of self-harming.

\section{CONCLUSION:}

Females have increased tendency to commit suicide than males especially in their reproductive age. Low socioeconomic status, cultural norms, unwanted pregnancies and ill health are the major causes.

KEYWORDS: Suicidal Mortality, Females, District Peshawar

\section{INTRODUCTION}

Every woman undergoes certain hormonal changes as soon she steps into her teens. These

\section{Correspondence}

Rizwan Zafar Ansari

Forensic Medicine \& Toxicology

Northwest School of Medicine

Email: dr.rizwan@nwsm.edu.pk Phone: 0324-4055667

https://doi.org/10.37762/jgmds.5-1.12 depression. Despite this in reproductive age group many other factors are also responsible for compelling females especially in their teen to commit act of suicide.
People who experience suicidal thoughts and feelings are suffering with tremendous emotional pain ${ }^{1}$. People who have died by suicide typically had overwhelming feelings of hopelessness, despair, and helplessness ${ }^{2}$. Suicide is not about moral weakness or a character flaw ${ }^{3}$. People considering suicide feel that their pain will never end, and that suicide is the only way to stop the suffering ${ }^{4}$. Suicide is a complex issue involving numerous factors and should not be attributed to any one single cause. Not all people who die by suicide have been diagnosed with a mental illness and not all people with a mental illness attempt to 
end their lives by suicide ${ }^{5}$. Most people who die by suicide give definite warnings of their intentions. Therefore, all threats of self-harm should be taken seriously. In addition, most people who attempt suicide are ambivalent and not entirely intent on dying ${ }^{5,6}$. Many suicides occur in a period of improvement when the person has the energy and the will to turn despairing thoughts into destructive action $^{7}$. However, a once-suicidal person is not necessarily always at risk; suicidal thoughts may return but they are not permanent, and, in some people, they may never return. It has been observed that in Pakistan major contributing factors are marital status, early divorces, no marriages, failed relationships and more restrictions for females than males. In India during the year 2008-2009, 98.1\% cases reported of suicide were dowry dispute, $72.8 \%$ physical abuse/rape, $62.2 \%$ no marriages or late marriages, $53.3 \%$ were the cases of illegitimate pregnancies $^{8,9}$.

\section{METHODOLOGY:}

All the cases of female autopsies were examined. Out of 98 cases of female autopsies 44 cases are identified as cases of self-harming. Data was collected by the duty Medicolegal officers from the record room of autopsy center. The physical age of the victim was correlated with the radiological age determined after examination of long bones. Women outside the reproductive age group and cases where manner of death was doubtful were excluded from the study. A data collection tool (Performa) was developed that include age of victim, mode and manner of death, place of death, number of attempts of suicide, history of extra marital affairs, any history of mental illness, physical violence.

\section{RESULTS:}

Forty-four (44) dead bodies of female victims were autopsied with confirmed history of suicide.
$13(30 \%)$ were adolescents between the age of $10-18$ years. $31(70.4 \%)$ were aged between 1948 years. 33 of the victims committed suicide due to health-related issues. $28(64 \%)$ victims used poisons. In almost all cases $(n=38)$ the incident happened when the victim was alone in house or left unattended. $30(68 \%)$ victims were brought to hospitals for treatment. 13 were found to have recurrent attempt of self-harming. The oldest victim belonging to reproductive age was 48 years old while the youngest female was just 11 years old. The frequency of intention to commit suicide is listed in Table 2. In 11 (25\%) cases the cause of death was either drug over dose or cannot be determined. It has also been observed that women suffering from underdeveloped breast and female secondary sexual characteristics were also found to be on the list of groups with a history of multiple attempts of suicide $16(36 \%)$. In one case the victim was physically torture by her inlaws. Two victims age 14 years and 34 years attempted suicide by jumping from the building. The reason was failure in exam and unemployment. Six females were found not virgin and out of them 3 were found pregnant on examination of uterus. As shown in Table 3, most of the incidents happened due to overdose of drugs. $10(23 \%)$ were found hanging inside their houses, $2(3 \%)$ attempted suicide by jumping from height. Only in $2(3 \%)$ cases suicide was due to sharp edge weapon. Almost all attempts of suicide $41(93 \%)$ occur at home or inside their working place. $30(68 \%)$ cases brought to emergency department out of which $25(83 \%)$ were drug over dose, and the minimum period of survival was few minutes whereas the maximum period was 17 days.

Table 1: Age Distribution of Suicide Victims

\begin{tabular}{|c|c|c|}
\hline $10-18$ years & $19-48$ years & Total $(n=44)$ \\
\hline $13(30 \%)$ & $31(70 \%)$ & $44(100 \%)$ \\
\hline
\end{tabular}




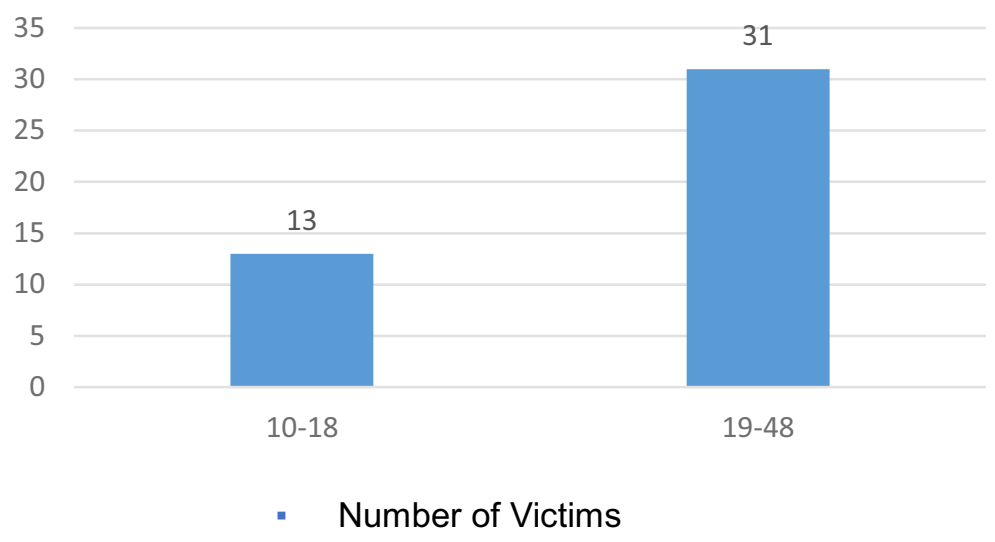

Figure 1: Number of Victims

Table 2: Intention to Commit Suicide

\begin{tabular}{|c|c|}
\hline Intention to Commit Suicide & Frequency (Percentage) \\
\hline Motive Unascertainable & $11(25)$ \\
\hline Female Related Beauty and Health Issues & $16(36)$ \\
\hline Extra Marital Issues & $8(18)$ \\
\hline Depression/Frustration & $6(14)$ \\
\hline Academic & $2(5)$ \\
\hline Unemployment & $1(2)$ \\
\hline Total & $44(100)$ \\
\hline
\end{tabular}

Table 3: Manner of Suicide

\begin{tabular}{|c|c|}
\hline Manner & Frequency (Percentage) \\
\hline Poison Ingestion & $28(64)$ \\
\hline Hanging & $10(23)$ \\
\hline Jump from the Building & $2(3)$ \\
\hline Cut Throat & $1(2)$ \\
\hline Cutting of Vain & $1(2)$ \\
\hline
\end{tabular}

\section{DISCUSSION:}

The tendency of self-harming has been increased many folds in the past 10 years $^{10}$. The rate of committing suicide is more in females than in males $^{9,10}$. The higher male gender suicide rate was due to more rigorous subjection of men variations and stressors of daily living and life as compared to females ${ }^{11}$. According to National Bureau of Crime Investigation of Pakistan 
(NBCIP) suicidal death has been among 10 major causes of death in Pakistan ${ }^{12}$. From a recent study conducted in Peshawar district concluded that females are more inclined to harm themselves to gain attention and sympathy of others. Most common method of self-harming was drug over dose. In some of the cases the patient deliberately ingests more than one poison ${ }^{13}$. The results of our study were similar to a study conducted in Faisalabad $^{14}$. In Faisalabad fatal deliberate selfharming was among top three causes of death between the ages of sixteen to thirty-five in females. A psychological autopsy approach to death investigation has revealed that psychiatric disorders are present in about $90 \%$ of deliberate cases of self-harming. Our findings contrasted with the findings observed in above mentioned study ${ }^{15}$. Our study suggested that female underdeveloped breast and other health related issues are dominated in our society followed by illegitimate relations, depression, frustration, academic failure and joblessness. It has been observed that in southern part of India and Pakistan, the most common method of committing suicide is hanging. In Geneva, Brazil and Israeli women adopted common methods like poisoning, abusive drug overdose and fall from height ${ }^{16}$. Forty one out of forty-four females preferred to commit suicide inside the four walls of the house. This high incidence at home can be attributed to the preference of the victims for a familiar home environment. For the investigating officer it is necessary to evaluate the psychological factors associated with the incident. In most of the cases the victim has past mental illness and depression. Our study suggests that such cases should have psychiatric counseling sessions. It is responsibility of the family members to help the victim to get out of trauma by giving exceptional care and importance. Most of the victims commit suicide when they were either alone or left unattended.

\section{CONCLUSION:}

Females have increased tendency to commit suicide than males especially in their reproductive age. Low socioeconomic status, cultural norms, unwanted pregnancies and ill health are the major causes.

\section{REFERENCES:}

1. Retterstol N. Suicide: A European Perspective. Cambridge: University Press; 1990.

2. Bertolote JM, Fleischmann A. A global perspective in the epidemiology of suicide. Suicidologi. 2015;7(2).

3. India PS. National Crime Records Bureau. Ministry of Home Affairs. New Delhi, India. 2011.

4. Kanchan T, Menon A, Menezes RG. Methods of choice in completed suicides: gender differences and review of literature. J Forensic Sci. 2009;54(4):938-42.

5. World Health Organization. Figures and facts about suicide. Geneva: WHO; 1999.

6. Monk M. Epidemiology of suicide. Epidemiology Rev. 1987;9:51-69.

7. Young people's health: a challenge for society. Report of a study group on young people and health for all by the year 2000, technical report series. Geneva: World Health Organization; 1986.

8. Phillips MR, Liu H, Zhang Y. Suicide and social change in China. Culture Med Psychiatry. 1999;23(1):25-50.

9. Harris C, Barraclough B. Excess mortality of mental disorder. $\mathrm{Br} J$ Psychiatry. 1998;173(1):11-53.

10. Cavanagh JT, Carson AJ, Sharpe M, Lawrie SM. Psychological autopsy studies of suicide: a systematic review. Psychological Med. 2003;33(3):395-405.

11. Ansari RZ. Incidence of poisoning in Peshawar. Int J Pathology. 16(1):16-20 
12. Scott KW. Suicide in Wolverhampton (19761990). Med Sci Law. 1994;34(2):99-105.

13. Kanchan T, Menezes RG. Suicidal poisoning in Southern India: gender differences. J Forensic Legal Med. 2008;15(1):7-14.

14. Peng LK, Choo AS. Suicide in Singapore, 1986. Aust NZ J Psychiatry. 1992;26(4):599608.
15. Nachman R, Yanai O, Goldin L, Swartz M, Barak Y, Hiss J. Suicide in Israel: 1985-1997. J Psychiatry Neuro Sci. 2002;27(6):423.

16. Saeed A, Bashir MZ, Khan D, Iqbal J, Raja $\mathrm{KS}$, Rehman A. Epidemiology of suicide in Faisalabad. J Ayub Med Coll Abbottabad. 2002;14(4):34-7. purpose. It includes scholarly 